\title{
The Class-A GPCR Dopamine D2 Receptor Forms Transient Dimers Stabilized by Agonists: Detection by Single-Molecule Tracking
}

\author{
Rinshi S. Kasai ${ }^{1}$ Shuichi V. Ito ${ }^{1} \cdot$ Ryo M. Awane $^{1} \cdot$ Takahiro K. Fujiwara $^{2}$ • \\ Akihiro Kusumi ${ }^{1,2,3}$
}

Received: 9 May 2017 / Accepted: 18 September 2017 / Published online: 7 November 2017

(C) The Author(s) 2017. This article is an open access publication

\begin{abstract}
Whether class-A G-protein coupled receptors (GPCRs) exist and work as monomers or dimers has drawn extensive attention. A class-A GPCR dopamine D2 receptor (D2R) is involved in many physiological and pathological processes and diseases, indicating its critical role in proper functioning of neuronal circuits. In particular, D2R homodimers might play key roles in schizophrenia development and amphetamine-induced psychosis. Here, using singlemolecule imaging, we directly tracked single D2R molecules in the plasma membrane at a physiological temperature of $37^{\circ} \mathrm{C}$, and unequivocally determined that D2R forms transient dimers with a lifetime of $68 \mathrm{~ms}$ in its resting state. Agonist addition prolonged the dimer lifetime by a factor of $\sim 1.5$, suggesting the possibility that transient dimers might be involved in signaling.
\end{abstract}

Keywords Dopamine receptor $\cdot \mathrm{G}$ protein-coupled receptor $(\mathrm{GPCR}) \cdot$ Plasma membrane $\cdot$ Cultured cell $\cdot$ Singlemolecule biophysics $\cdot$ Dimerization

Akihiro Kusumi

akihiro.kusumi@OIST.jp

kusumiaki@gmail.com

1 Institute for Frontier Life and Medical Sciences, Kyoto University, Kyoto 606-8507, Japan

2 Center for Meso-Bio Single-Molecule Imaging (CeMI), Institute for Integrated Cell-Material Sciences (WPI-iCeMS), Kyoto University, Kyoto 606-8507, Japan

3 Membrane Cooperativity Unit, Okinawa Institute of Science and Technology, Okinawa 904-0495, Japan

\section{Introduction}

G-protein-coupled receptors (GPCRs) constitute the largest protein superfamily in the human genome, including about 800 genes. They are involved in many physiological processes and are currently one of the most prominent pharmacological targets. Despite the importance of GPCRs, the fundamental question of whether GPCRs form and work as monomers, dimers, and/or greater multimers have remained unanswered [1-16]. The functional units of class-C GPCRs, including metabotropic glutamate receptor 1 [17-21] and $\mathrm{GABA}_{\mathrm{B}}$ receptors [22-24], are generally considered to be constitutive homo- and/or hetero-dimers. However, our knowledge about the oligomeric states of the largest class of GPCRs, the class-A group GPCRs, is quite limited. They might exist as monomers [3, 4, 16, 25], dimers [26-32], constitutive multimers [33] and/or dynamically interchanging monomers and dimers [34-39], even in the ER membrane [37].

The first step toward resolving this issue is to determine whether class-A GPCRs form dimers and multimers in the plasma membranes (PMs) of living cells, rather than relying on in vitro experiments [34-39], and to employ methods that can directly observe the dynamic interconversions between monomers and di-/multimers. Previously, by developing a single fluorescent-molecule imaging method, the dynamic monomer-dimer equilibrium for a GPCR, the $\mathrm{N}$-formyl peptide receptor (FPR), was determined in living cells, for the first time ever for any membrane molecule [35]. In quiescent cells before agonist stimulation of FPR, the dimer-monomer 2D-equilibrium constant was 3.6 copies $/ \mu \mathrm{m}^{2}$, with $2 \mathrm{D}$-dissociation and $2 \mathrm{D}$-association rate constants of $11.0 \mathrm{~s}^{-1}$ and 3.1 [copies $\left./ \mu \mathrm{m}^{2}\right]^{-1} \mathrm{~s}^{-1}$, respectively, at $37^{\circ} \mathrm{C}$. With the physiological FPR expression level of $\sim 2.1$ receptor copies/ $\mu \mathrm{m}^{2} \quad(\sim 6000$ copies/ 
neutrophil), monomers continually convert into dimers every $150 \mathrm{~ms}$, dimers dissociate into monomers in $91 \mathrm{~ms}$ (dimer lifetime; inverse the 2D-dissociation rate constant), and at any moment, 2500 and 3500 receptor molecules participate in transient dimers and monomers, respectively. Transient homodimers of the class-A GPCR were also found for M1 muscarinic receptor [34], $\beta 1$-adrenergic receptor (AR), $\beta 2-\mathrm{AR}$ [36], and dopamine D2 receptor (D2R) [39]. Interestingly, in the case of FPR, even after stimulation of the antagonist, the monomer-dimer equilibrium was not affected [35].

In the present study, to advance this line of research further, we further examined whether a class-A GPCR, $\mathrm{D} 2 \mathrm{R}$, forms transient or prolonged dimers and whether ligation influences dimerization. We selected D2R because it plays a critical role in the development of psychosis, as illustrated by the fact that many antipsychotics act by modulating D2R. Furthermore, D2R dimerization might be involved in the pathophysiology of schizophrenia as well as in the sensitized state after exposure to amphetamine, a drug that can cause psychosis [40]. Furthermore, D2R might play important roles in other tissues: in addition to neurons in the cerebral cortex, olfactory tubercle, and hippocampus, D2R is ubiquitously expressed in various tissues, including blood vessels, adrenal gland, heart, and kidney [41].

D2R homo-dimerization has been a controversial subject matter. On the one hand, constitutive dimerization was reported [42], but on the other hand, transient dimerization was suggested [11, 39, 43]. Meanwhile, agonist stimulation was found to reorient the fourth transmembrane helix in the constitutive dimer [42], suggesting that allosteric communication between the protomers of D2R dimers modulated the protomer activation [44]. Furthermore, the presence of monomers and various multimers up to pentamers of D2R has been reported [39, 45].

Previously, using single-molecule imaging, Tabor et al. [39] detected transient D2R homodimers with a lifetime of $\sim 0.5 \mathrm{~s}$, which was longer than that we found for FPR (91 ms) by a factor of 5.5. It should be noted that our experiments for FPR were performed at $37^{\circ} \mathrm{C}$, whereas the result for D2R dimer lifetime by Tabor et al. was obtained at $24^{\circ}$ C. Meanwhile, other data of GPCR homodimer lifetimes were all conducted at lower temperatures: M1 muscarinic receptor (lifetime $\sim 0.7 \mathrm{~s}, 8 \mathrm{x}$ longer than FPR dimer lifetime) at $23^{\circ} \mathrm{C}$ [34] and $\beta 1$ - and $\beta 2$-AR (lifetime $\sim 5 \mathrm{~s}, 55 \mathrm{x}$ longer than FPR dimer lifetime) at $20.5^{\circ} \mathrm{C}$. Due to such variations, we consider that the GPCR homodimer lifetimes should be better defined, by observing them at a physiological temperature of $37^{\circ} \mathrm{C}$.

Furthermore, to investigate the physiological relevance of GPCR homodimers, the effect of agonist on the homodimer lifetime would be quite important. The results about this point reported in the literature are quite varied. No effects were detected on the homodimers of FPR [6, 35], $\beta 1$ - and $\beta 2-\mathrm{AR}[30,36,46], \mathrm{M} 1$ muscarinic receptor [30], 5HT2c [47] and 5HT4 [26] serotonin receptor, and neurotensin receptor 1 [33], as well as $\beta 1-\beta 2$ AR heterodimers [46]. On the other hand, an increase of apparent dimer fraction was observed for D2R upon agonist addition [39], which might be due to the agonist-induced rearrangements of the transmembrane $\alpha$-helices within the D2R homodimers [48] (similar findings were made for CCR2 [49] and CXCR4 [49]).

Here, using single fluorescent-molecule imaging-tracking, we unequivocally detected transient $\mathrm{D} 2 \mathrm{R}$ dimers in the live-cell PM, and determined their lifetimes at $37^{\circ} \mathrm{C}$. Furthermore, we found that the $\mathrm{D} 2 \mathrm{R}$ dimer lifetimes were prolonged after agonist stimulation.

\section{Materials and Methods}

\section{Cell Culture, cDNA Construction, and Expression in CHO-K1 Cells}

CHO-K1 cells, which do not respond to dopamine stimulation [50], were cultured in Ham's F12 medium (Sigma) supplemented with $10 \%$ (v/v) FBS, 100 units/ml penicillin, and $0.1 \mathrm{mg} / \mathrm{ml}$ streptomycin. The cells were transfected with the cDNA encoding acyl-carrier protein (ACP)-tagged human D2R (cDNA encoding the short variant; Addgene) in the plasmid vector pcDNA3.1(+) (Life Technologies) using LipofectAMINE PLUS (Life Technologies), according to the manufacturer's recommendations. Transfected cells were seeded in glass-base dishes (35-mm $\phi$ with a glass window of $12 \mathrm{mm \phi}, 0.12-0.17$-mm-thick glass; Iwaki), and cultured for $24-48 \mathrm{~h}$ before use. ACP is known to be monomeric [51].

The treatments of the cells with agonists and neutral antagonists were performed by adding $1 \mathrm{ml}$ solutions of 30 $\mu \mathrm{M}$ dopamine (Wako), $30 \mu \mathrm{M}$ (-)-quinpirole (SIGMAAldrich) or $200 \mathrm{nM}(+)-\mathrm{UH}-232$ (TOCRIS), in Hank's balanced salt solution (HBSS, Nissui) buffered with $2 \mathrm{mM}$ piperazine-N,N'-bis(ethanesulfonic acid) (PIPES) from Dojindo (Kumamoto, Japan), at pH 7.4 (P-HBSS).

\section{Labeling of D2R with the Fluorescent Dye ATTO594}

ACP-tagged D2R expressed in the PM was labeled with ATTO594 (ATTO-TECH), by incubating the cells with 2 $\mu \mathrm{M}$ ATTO594-Coenzyme A (custom-synthesized by Shinsei Kagaku, Osaka, Japan, by conjugating ATTO594maleimide to Coenzyme A-SH [New England Biolabs]) and $1 \mu \mathrm{M}$ phosphopantetheine transferase at $\sim 25^{\circ} \mathrm{C}$ for 20 min, which are the conditions that achieved $\sim 95 \%$ labeling of ACP [52]. The cells were washed with P-HBSS 
three times, and then the washed cells were subjected to microscopic observations. The cells exhibiting the presence of 0.4-0.8 ATTO594-ACP-D2R spots/ $\mu \mathrm{m}^{2}$ were used for single-molecule imaging experiments.

\section{Single Fluorescent-Molecule Video Imaging, Detection of Colocalization-Codiffusion, and Determination of Dimer Lifetimes}

Single molecules of the fluorescently-labeled ACP-D2R expressed in the bottom PM were observed at $37^{\circ} \mathrm{C}$, using a home-built objective-lens-type total internal reflection microscope based on an Olympus IX-70 inverted microscope [53, 54], with a 100x objective lens (numerical aperture of 1.49; Olympus UAPON100XOTIRF). Fluorescent images were projected onto a two-stage microchannel plate intensifier (C8600-03, Hamamatsu Photonics), coupled to a scientific complementary metal-oxide-semiconductor camera operated at 30 or 250 $\mathrm{Hz}$ (C11440-22CU, Hamamatsu Photonics). The acquired image sequence was directly recorded on a solid-state drive installed on a personal computer. Fluorescent spots were identified by using a home-made computer program, as described previously [55].

Colocalization of two fluorescent spots (molecules) of the same color (the same ATTO594 probe) was detected when the two fluorescent molecules became localized within $220 \mathrm{~nm}$ from each other [35, 54]. An imagecorrelation analysis revealed a threshold value of $220 \mathrm{~nm}$ for detecting one or two peaks (for Alexa594 and DY547, $219 \pm 9.0 \mathrm{~nm}$, Kasai et al. [35]). Obviously, a scale of 220 $\mathrm{nm}$ is much greater than the molecular scale. Therefore, in addition to the colocalization due to the specific direct/ indirect molecular binding as well as the entrapment in the same nano-domain, the incidental approaches of molecules within $220 \mathrm{~nm}$, termed "incidental colocalization", will often occur. However, although unassociated molecules may track together by chance over a short distance, the probability of this occurring for multiple frames is small, and therefore, longer colocalization durations imply the presence of molecular interactions between the two molecules, rather than incidental approaches within $220 \mathrm{~nm}$ (see the Results section). A similar method for detecting colocalization-codiffusion has been proposed [56].

Each time a colocalization-codiffusion event of D2R molecules was detected, its duration was measured, and after many such colocalization events were observed, a histogram showing the distribution of colocalization durations was obtained. The histogram could be fitted by a single exponential function, which provided a decay constant (lifetime; $\tau_{\text {observed }}$ ). This value was then corrected for the photobleaching lifetime ( $\tau_{\text {bleaching }}$ ) to obtain the duration of apparent colocalization ( $\left.\tau_{\text {apparent colocalization }}\right)$, using the equation $\left[\tau_{\text {observed }}{ }^{-1}-2 \tau_{\text {bleaching }}{ }^{-1}\right]^{-1}=\tau_{\text {apparent colocalization }}$ [35, 57]. (In our previous work [35], by comparing the results obtained by recordings at a 4-ms time resolution, we showed that $\tau_{\text {observed }}$ of $110 \mathrm{~ms}$ could be determined precisely by $33-\mathrm{ms}$-resolution observations [normal video rate]. Therefore, we employed normal-video-rate observations in the present study.)

In principle, since the histogram of individual dimer durations should include the contributions of both specific and incidental colocalization events, the durations of which are described by complex functions. Nevertheless, we found that the incidental colocalization duration distribution could be quite-well described by a single exponential function with an incidental colocalization lifetime of $19 \pm 0.66 \mathrm{~ms}$, using a monomer reference molecule, ACP linked to the transmembrane domain of the low-density lipoprotein receptor, called ACP-TM [35]. Furthermore, as described in the previous paragraph, the distribution of colocalization durations could be fitted by a single exponential function, probably due to the insufficient time resolution and/or poor signal-to-noise ratios, suggesting that its lifetime, $\tau_{\text {apparent }}$ colocalization, closely represents the distribution of the sum of the durations of the following three events: duration from the encounter of two molecules within the distance of 220 $\mathrm{nm}$ until the binding of two molecules (duration 1), that of actual binding of two molecules (duration 2), and that from the separation of two molecules until they become separated over the distance of $220 \mathrm{~nm}$ (duration 3). Therefore, at the time resolution and signal-to-noise ratio of the present instrument, the best estimate of the binding duration of the

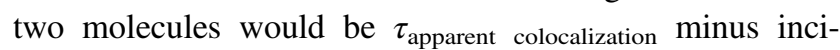
dental colocalization lifetime of $19 \pm 0.66 \mathrm{~ms}$ (assuming that this lifetime is close to the sum of duration 1 and duration 3). The pure incidental colocalization events are not included in this argument, because the fitting was performed from the second bin (33 ms and longer), which excludes the majority of incidental events.

Although we tracked the signal intensities as well as the $(\mathrm{x}, \mathrm{y})$-coordinates of single molecules, we used the signal intensity information only for the purpose of confirming colocalization. In our single-molecule tracking with the signal intensity, we hardly observed any spots exhibiting two-step photobleaching. This observation excludes the possibility that we missed fluorescent spots of dimers that last for very long durations (if we had tracked colocalization using only the $(\mathrm{x}, \mathrm{y})$-coordinates of single molecules, long lasting dimers might appear like single molecules, and thus we might miss the long-lasting dimers). Meanwhile, even when two fluorescent spots partially overlapped, although the signal intensities of such spots might appear to be those of dimers, the two molecules were often found to be separated from each other by a distance longer than 220 $\mathrm{nm}$ (thus, no colocalization, and thus no binding), and 
therefore, simple intensity measurements were not useful for unequivocally detecting colocalization.

\section{Results}

\section{D2R Molecules Exhibited Transient Colocalization- Codiffusion}

All single-molecule tracking experiments were performed at $37^{\circ} \mathrm{C}$, at a time resolution of $33 \mathrm{~ms}$ (video rate) or $4 \mathrm{~ms}$. $\mathrm{D} 2 \mathrm{R}$ conjugated at its $\mathrm{N}$-terminus with ACP was expressed in $\mathrm{CHO}$ cells, which do not express endogenous dopamine receptors, and D2R in the PM was fluorescently labeled by covalently conjugating ATTO594. This method allowed almost complete fluorescent labeling of D2R ( $>95 \%$, George et al. [52]). The expression levels of D2R in the PM were adjusted to $0.4-0.8$ copies $/ \mu \mathrm{m}^{2}$.

The D2R molecules in the PM were observed at the level of single molecules. In quiescent cells, as shown in Figs. 1a and $\mathrm{b}$, most D2R molecules ( 80\%) were mobile, exhibiting a median diffusion coefficient of $0.10 \mu \mathrm{m}^{2} / \mathrm{s}$ in the time windows of 67 and $133 \mathrm{~ms}\left(D_{100 \mathrm{~ms}}\right)$ (Fig. $1 \mathrm{a} ; 0.14 \mu \mathrm{m}^{2} / \mathrm{s}$ when only mobile D2R molecules were examined; see the caption to Fig. 1a for details). The typical images and trajectories displayed in Fig. 1b indicate that D2R molecules undergo diffusion and frequent transient colocalizationcodiffusion with other D2Rs, and such colocalizationcodiffusion occurred frequently throughout the PM observed here.

\section{Durations of Colocalization-Codiffusion of Two D2R Molecules}

Since each fluorescent spot representing a single fluorescent molecule is much larger than the molecule itself $(\sim 500 \mathrm{~nm}$ vs. $\sim 5 \mathrm{~nm}$ in diameter), even unassociated molecules become colocalized without molecular interactions and might track together by chance over a short distance. However, the probability of such incidental codiffusion events occurring for multiple frames is small, and therefore, longer colocalization implies the occurrence of molecular interactions between two molecules. Previously, we employed a monomer-reference molecule, ACP linked to the transmembrane domain of the low-density lipoprotein receptor, ACP-TM, and found that the duration of incidental colocalization-codiffusion of ACP-TM is $19 \pm 0.66 \mathrm{~ms}$ [35].

In the present research, each time we found a colocalization-codiffusion event of D2R molecules, we measured its duration, and after observing many such colocalization events, we obtained the distribution of colocalization durations (Fig. 2a). The histogram could be fitted by a single exponential function, providing a decay constant

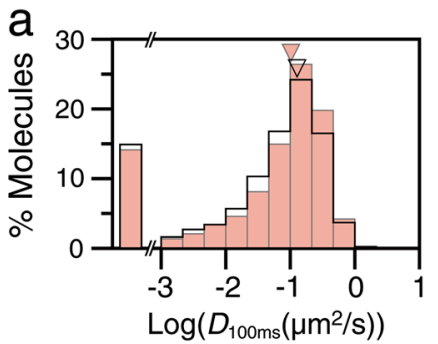

b

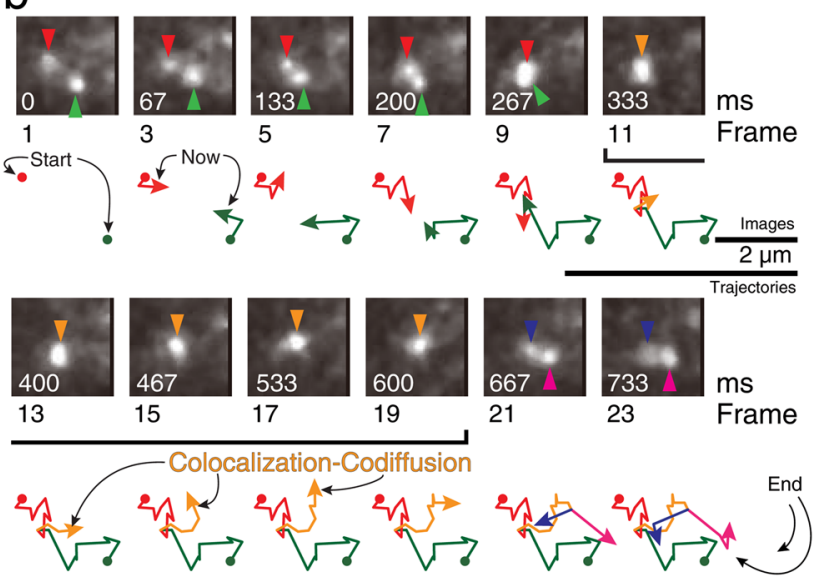

Fig. 1 D2R molecules continually form transient dimers. a The histograms showing the distributions of the diffusion coefficients evaluated in the interval between 67 and $133 \mathrm{~ms}\left(D_{100 \mathrm{~ms}}\right)$, before (pink bars) and 20-120 s after dopamine (agonist) stimulation (black open bars). Since even the ATTO594 molecules bound to the glass exhibit apparent mobility due to noise, with apparent $D_{100 \mathrm{~ms}}$ up to $0.01 \mu \mathrm{m}^{2} / \mathrm{s}$, D2R molecules exhibiting apparent $D_{100 \mathrm{~ms}}$ greater (smaller) than 0.01 $\mu \mathrm{m}^{2} / \mathrm{s}$ were defined as (im)mobile molecules. The percentages of immobile molecules were practically unchanged $(20 \%)$ after the addition of dopamine. The triangles indicate the median values including immobile D2R molecules: 0.10 and $0.084 \mu \mathrm{m}^{2} / \mathrm{s}$ before and after stimulation, respectively. The median values excluding immobile molecules (molecules with $D_{100 \mathrm{~ms}}$ smaller than $0.01 \mu \mathrm{m}^{2} / \mathrm{s}$ ) were 0.14 and $0.13 \mu \mathrm{m}^{2} / \mathrm{s}$ before and after stimulation, respectively. Before and after stimulation, 2183 and 2595 molecules in six cells were inspected, respectively (no statistically significant difference after dopamine addition, using the Brunner-Munzel test). b A typical video sequence and trajectories of single D2R molecules undergoing temporary colocalization-codiffusion, recorded at a 33-ms resolution (video rate; without ligation). The two molecules (red and green triangles in the images and trajectories) first became colocalized in video frame 11 (333 ms), diffused together for 10 video frames $(333 \mathrm{~ms}$, yellow trajectories; Colocalization-Codiffusion), and then separated (blue and magenta triangles and trajectories)

(lifetime; $\tau_{\text {observed }}$ ) of $82.6 \pm 4.2 \mathrm{~ms}$ (Fig. 2a) (throughout this report, the fitting error of the $68.3 \%$ confidence limit is given as the fitting parameter error, which equals the standard error of the determined parameter).

The decay constant was corrected for the photobleaching lifetime of the fluorescent probe ATTO594 $(2.98 \pm 0.29 \mathrm{~s}$; Fig. 2b), providing 87.4 ( $87 \mathrm{~ms}$ for two significant digits) \pm $4.7 \mathrm{~ms}$ after correction for its photobleaching lifetime. For further discussions of the colocalization lifetimes, see 

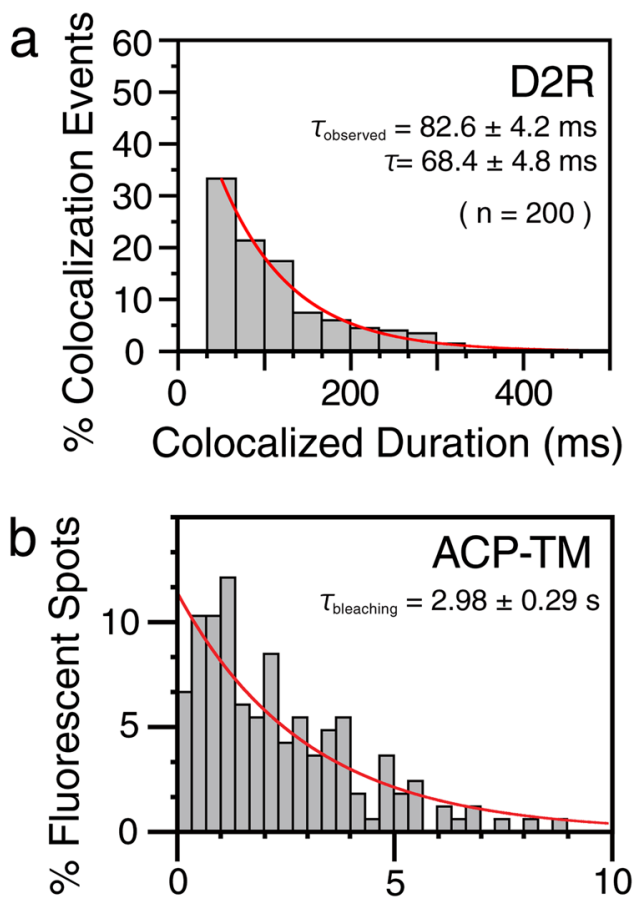

Fluorescence Lifetime (s)

Fig. 2 D2R dimer lifetime determined by single-molecule tracking. a Histograms showing the distributions of the durations of individual colocalization events for D2R and ACP-TM, observed at a time resolution of $33 \mathrm{~ms}$. See Materials and Methods for details. b The distribution of photobleaching lifetimes of ATTO594, providing an exponential photobleaching lifetime of $2.98 \pm 0.29 \mathrm{~s}$ ( $n=165$ molecules) by single exponential fitting. The determination was made with ACP [ATTO594]-TM expressed in the PM of CHO cells. By singleexponential fitting, the exponential lifetime for D2R colocalization $\left(\tau_{\text {observed }}\right)$ was found to be $82.6 \pm 4.2 \mathrm{~ms} \quad(n=200$ colocalization events). This value was corrected for photobleaching, using the photobleaching lifetime of $2.98 \mathrm{~s}$, providing a corrected colocalization lifetime ( $\tau_{\text {apparent colocalization }}$ ) of $87.4 \pm 4.7 \mathrm{~ms}$. Since this value is the sum of the actual binding time $(\tau)$ and the duration for the incidental approach (+separation), which is $19 \mathrm{~ms}$, the D2R homodimer lifetime $\tau$ was estimated to be $68.4 \pm 4.8 \mathrm{~ms}(87.4-19 \mathrm{~ms})$

Materials and Methods (Single fluorescent-molecule video imaging, detection of colocalization-codiffusion, and determination of dimer lifetimes).

\section{D2R Forms Homodimers, with a Lifetime of $68 \mathrm{~ms}$}

As the colocalization lifetime of D2R $(87 \mathrm{~ms})$ is much longer than that of ACP-TM (19 ms; Kasai et al. [35]) $(P=$ $2.2 \times 10^{-16}$, Brunner-Munzel test), we concluded that the $\mathrm{D} 2 \mathrm{R}$ monomers interact with each other; i.e., D2R forms transient homodimers. Since the colocalization lifetime of ACP-TM (19 ms) represents the duration of incidental approaches of two molecules without specific molecular interactions, the actual binding duration (dimer lifetime; $\tau$ ) of D2R molecules can be estimated by subtracting $19 \mathrm{~ms}$ from $87 \mathrm{~ms}$, providing $68 \mathrm{~ms}$ (see Materials and Methods).
Table 1 Summary of the homodimer lifetimes of D2R before and after the addition of agonist or neutral antagonist

\begin{tabular}{lcll}
\hline & $\begin{array}{l}\text { Dimer } \\
\text { lifetime (ms) }\end{array}$ & $\begin{array}{l}\text { \# of } \\
\text { events }\end{array}$ & $\begin{array}{l}\text { P (vs. D2R } \\
\text { before ligation) }\end{array}$ \\
\hline $\begin{array}{l}\text { Before ligation } \\
+ \text { Dopamine (natural }\end{array}$ & $68.4 \pm 4.8$ & 200 & N.A. \\
$\begin{array}{l}\text { agonist) } \\
\text { +Quinpirole (agonist) } \\
+ \text { UH-232 (neutral } \\
\text { antagonist) }\end{array}$ & $70.5 \pm 11.5$ & 232 & 0.0328 \\
\hline
\end{tabular}

Note that, because this duration might be the result of many dissociation-rebinding events, this number should be considered to be the collective lifetime when the dimerization occurred. Dimer lifetimes, $\tau$ 's, observed under various conditions are summarized in Table 1.

We previously found that the FPR homodimer lifetime was $\sim 90 \mathrm{~ms}$. Therefore, the lifetime of the transient homodimers of D2R is comparable to that of FPR homodimers, but slightly (25\%) shorter. Previously, using singlemolecule imaging at a lower frame rate (19.32 frames per second vs. 30 frames per second employed here), Tabor et al. [39] detected transient D2R homodimers with a lifetime of $\sim 0.5 \mathrm{~s}$ at $24^{\circ} \mathrm{C}$, which was longer than that found here $\left(68 \mathrm{~ms}\right.$ at $\left.37^{\circ} \mathrm{C}\right)$ by a factor of 7.4.

We hardly detected any oligomers greater than dimers under the expression levels employed here (0.4-0.8 ATTO594-ACP-D2R spots $/ \mu^{2}$ in the PM). At much higher expression levels, oligomers might form. To the best of our knowledge, the physiological expression levels of D2R have not been reported.

\section{Agonist Stimulation Slightly Stabilized Transient Dimers, in Contrast to a Neutral Antagonist}

The effects of agonists on the D2R homodimer lifetime was investigated by incubating the cells expressing D2R in the presence of agonists ( $15 \mu \mathrm{M}$ dopamine or $15 \mu \mathrm{M}$ quinpirole) [58], or a neutral antagonist $(0.1 \mu \mathrm{M} \mathrm{UH}-232)$ [59] for 20-120 s. This incubation time was selected because intracellular $\mathrm{Ca}^{2+}$ mobilization was detected within $20 \mathrm{~s}$ after agonist addition $\left(15 \mu \mathrm{M}\right.$; no intracellular $\mathrm{Ca}^{2+}$ mobilization was found after the addition of a neutral agonist, UH-232, for $2 \mathrm{~min}$ ).

The duration histograms for D2R colocalizationcodiffusion before and after the incubations of the cells with these compounds are shown in Fig. 3. After single exponential fitting of these histograms, correction for probe photobleaching, and then subtraction of the incidental overlapping lifetime of $19 \mathrm{~ms}$, the D2R homodimer lifetimes $(\tau)$ were determined to be $98.6 \pm 8.3 \mathrm{~ms}, 103.5 \pm 9.3$ $\mathrm{ms}$, and $70.5 \pm 11.0 \mathrm{~ms}$ after the additions of dopamine, 


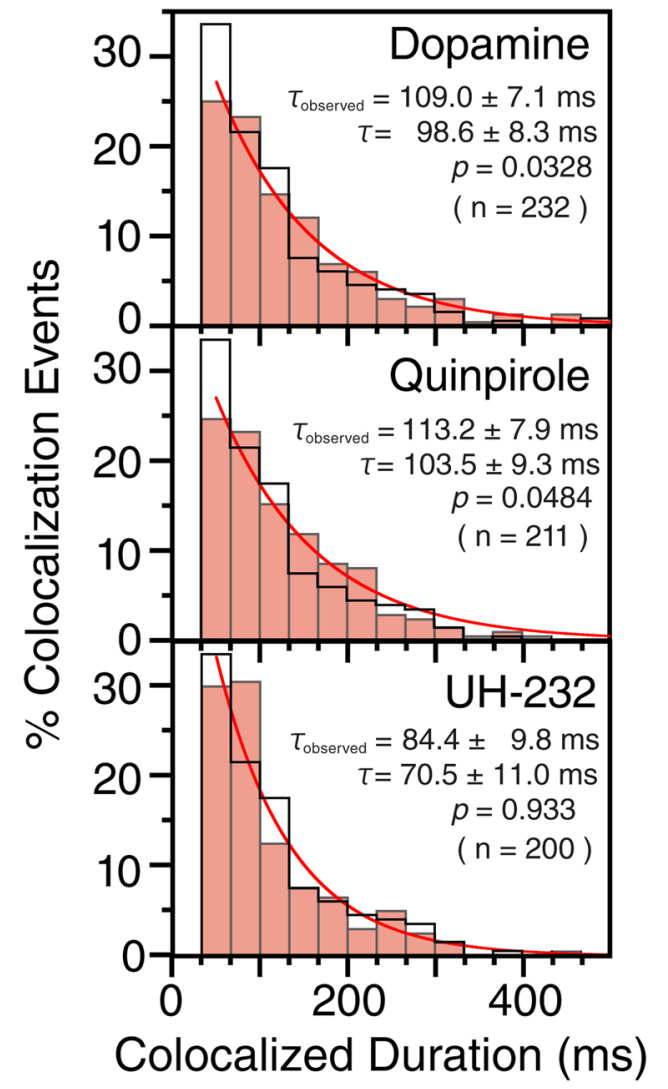

Fig. 3 D2R dimer lifetimes after treatments with the D2R agonists and neutral antagonist. Histograms showing the distributions of the durations of individual colocalization events for D2R 20-120 s after the treatments with the D2R agonists, dopamine and quinpirole, and the neutral antagonist, UH-232 (pink bars), as compared with those before ligation (black open bars; same as those shown in Fig. 2a). The values of $\tau_{\text {observed }}$ were determined to be $109.0 \pm 7.1 \mathrm{~ms}, 113.2 \pm 7.9 \mathrm{~ms}$, and $84.4 \pm 9.8 \mathrm{~ms}$, after the additions of dopamine, quinpirole, and UH232 , respectively. After corrections for the photobleaching lifetime and subtraction of the incidental colocalization lifetime $(19 \mathrm{~ms})$, the $\tau$ values for D2R homodimers were determined to be $98.6 \pm 8.3 \mathrm{~ms}$, $103.5 \pm 9.3 \mathrm{~ms}$, and $70.5 \pm 11.0 \mathrm{~ms}$ after the additions of dopamine, quinpirole, and UH-232, respectively

quinpirole, and UH-232, respectively. Namely, agonist stimulation significantly prolonged the lifetimes by a factor of $\sim 1.5$, whereas the neutral antagonist did not affect the D2R homodimer lifetime $(P=0.033,0.048$, and 0.93 , respectively, using the Brunner-Munzel test; summarized in Table 1).

\section{Discussion}

Whether a class-A GPCR D2R forms dimers, and if so, whether the dimers are transient or constitutive dimers, have been controversial subjects $[42,43]$. In the present research, our single-molecule imaging-tracking at a time resolution of $33 \mathrm{~ms}$ unequivocally showed that $\mathrm{D} 2 \mathrm{R}$ forms transient homodimers with a lifetime of $68 \mathrm{~ms}$ at $37^{\circ} \mathrm{C}$. This result is quite consistent with a homodimer lifetime of $90 \mathrm{~ms}$ for FPR observed by us at $37{ }^{\circ} \mathrm{C}$ [35]. Meanwhile, the D2R homodimer lifetime was found to be much longer $(\sim 0.5 \mathrm{~s})$ at $24{ }^{\circ} \mathrm{C}$ [39], a factor of 7.4 longer than that found here. Other class-A GPCRs, M1 muscarinic receptor and $\beta 1$ - and $\beta 2$ $\mathrm{AR}$, were also found to form transient homodimers with longer lifetimes of $0.7 \mathrm{~s}$ at $23{ }^{\circ} \mathrm{C}$ [34] and $5 \mathrm{~s}$ at $20.5{ }^{\circ} \mathrm{C}$ [36], respectively. Taken together, transient homodimerization is likely to be a general physical property of the class-A GPCRs, and thus homodimers may play some important roles in GPCR signaling and/or regulation. In addition, because temperature strongly affects the homodimer lifetime of D2R (between a lower temperature of $24^{\circ}$ $\mathrm{C}$ and the physiological temperature of $37^{\circ} \mathrm{C}$ ) and probably those of other GPCRs, the activation energy for homodimer formation is quite large (Q10 for D2R is likely to be much greater than 3 , and that for $\beta 1$ - and $\beta 2$-AR might reach 30 or more).

Furthermore, we found that the two agonists for D2R both prolonged the homodimer lifetime, whereas the neutral antagonist did not. The increase in the homodimer lifetime by the agonist binding was only by a factor of $\sim 1.5$, but if each subunit of the dimer participates in the downstream signaling, then the signal emitted by the D2R homodimer would increase by a factor of $2.3(1.5 \times 1.5)$. These results are quite consistent with the finding by Tabor et al. [39], in which agonist addition increased apparent dimer fraction of D2R. In previous analyses, the addition of agonists for FPR [35] and $\beta 1$ - and $\beta 2$-AR [36] did not change the homodimer lifetimes, and therefore, this is the first example in which the dimer lifetime was increased by agonist addition. Although the biological significance of these differences among GPCRs is not clear, our results are consistent with the findings reported by Wang et al. [40], in which schizophrenia, an amphetamine-induced sensitized state, and acute amphetamine exposure were found to enhance dimerization of D2R without altering its expression levels.

Meanwhile, a pull-down assay after chemical crosslinking revealed that another class-A GPCR, CCR2, was monomeric before stimulation, but agonist addition induced dimer formation [60]. Further studies on the effects of agonists on GPCR homodimerization are required, based on the present understanding that class-A GPCRs are likely to form transient homodimers with lifetimes shorter than $100 \mathrm{~ms}$.

Acknowledgements This research was supported in part by Grantsin-Aid for Scientific Research from the Ministry of Education, Culture, Sports, Science and Technology (MEXT) of the Japanese government to R.S.K. and A.K. This research was supported in part by Grants-inAid for scientific research from the Japan Society for the Promotion of Science (Wakate B and Kiban C to R. S. K. [26870292, 17K07333, respectively], Kiban B to T. K. F. [16H04775], and Kiban A and S to A. K. [24247029 and 16H06386, respectively]), Grants-in-Aid for Innovative Areas from the Ministry of Education, Culture, Sports, Science and Technology (MEXT) of Japan to R. S. K. (24115511) and 
to T. K. F. (26115707 and 15H01212) and a grant from Core Research for Evolutional Science and Technology (CREST) project of "Creation of Fundamental Technologies for Understanding and Control of Biosystem Dynamics" of Japan Science and Technology Agency (JST) to A. K. (JPMJCR14W2). WPI-iCeMS of Kyoto University is supported by the World Premiere Research Center Initiative (WPI) of the MEXT.

Author Contributions RSK and AK conceived this research, designed the experiments, and wrote the paper. RSK, SVI, and RMA performed the experiments and analyses. TKF developed the analysis software. All authors participated in the revisions of the manuscript and approved the final version of the manuscript.

\section{Compliance with Ethical Standards}

Conflict of Interest The authors declare that they have no competing interests.

Open Access This article is distributed under the terms of the Creative Commons Attribution 4.0 International License (http://crea tivecommons.org/licenses/by/4.0/), which permits unrestricted use, distribution, and reproduction in any medium, provided you give appropriate credit to the original author(s) and the source, provide a link to the Creative Commons license, and indicate if changes were made.

\section{References}

1. Overton, M. C., \& Blumer, K. J. (2002). The extracellular Nterminal domain and transmembrane domains 1 and 2 mediate oligomerization of a yeast $\mathrm{G}$ protein-coupled receptor. Journal of Biological Chemistry, 277(44), 41463-41472.

2. Meyer, B. H., Segura, J. M., Martinez, K. L., Hovius, R., George, N., Johnsson, K., \& Vogel, H. (2006). FRET imaging reveals that functional neurokinin-1 receptors are monomeric and reside in membrane microdomains of live cells. Proceedings of the National Academy of Sciences of the United States of America, 103(7), 2138-2143.

3. Ernst, O. P., Gramse, V., Kolbe, M., Hofmann, K. P., \& Heck, M. (2007). Monomeric $G$ protein-coupled receptor rhodopsin in solution activates its $\mathrm{G}$ protein transducin at the diffusion limit. Proceedings of the National Academy of Sciences of the United States of America, 104(26), 10859-10864.

4. Whorton, M. R., Bokoch, M. P., Rasmussen, S. G., Huang, B., Zare, R. N., Kobilka, B., \& Sunahara, R. K. (2007). A monomeric $\mathrm{G}$ protein-coupled receptor isolated in a high-density lipoprotein particle efficiently activates its $\mathrm{G}$ protein. Proceedings of the National Academy of Sciences of the United States of America, 104(18), 7682-7687.

5. Harikumar, K. G., Happs, R. M., \& Miller, L. J. (2008). Dimerization in the absence of higher-order oligomerization of the $\mathrm{G}$ protein-coupled secretin receptor. Biochimica et Biophysica Acta, 1778(11), 2555-2563

6. Kasai, R. S., \& Kusumi, A. (2014). Single-molecule imaging revealed dynamic GPCR dimerization. Current Opinion in Cell Biology, 27, 78-86.

7. Latty, S. L., Felce, J. H., Weimann, L., Lee, S. F., Davis, S. J., \& Klenerman, D. (2015). Referenced single-molecule measurements differentiate between GPCR oligomerization states. Biophysical Journal, 109(9), 1798-1806.
8. Jonas, K. C., Fanelli, F., Huhtaniemi, I. T., \& Hanyaloglu, A. C. (2015). Single molecule analysis of functionally asymmetric G protein-coupled receptor (GPCR) oligomers reveals diverse spatial and structural assemblies. Journal of Biological Chemistry, 290 (7), 3875-3892.

9. Cai, X., Bai, B., Zhang, R., Wang, C., \& Chen, J. (2017). Apelin receptor homodimer-oligomers revealed by single-molecule imaging and novel G protein-dependent signaling. Scientific Reports, 7, 40335 .

10. Navarro, G., Cordomi, A., Zelman-Femiak, M., Brugarolas, M., Moreno, E., Aguinaga, D., Perez-Benito, L., Cortes, A., Casado, V., Mallol, J., Canela, E. I., Lluis, C., Pardo, L., Garcia-Saez, A. J., McCormick, P. J., \& Franco, R. (2016). Quaternary structure of a G-protein-coupled receptor heterotetramer in complex with $\mathrm{Gi}$ and Gs. BMC Biology, 14, 26.

11. Kaczor, A. A., Jorg, M., \& Capuano, B. (2016). The dopamine D2 receptor dimer and its interaction with homobivalent antagonists: Homology modeling, docking and molecular dynamics. Journal of Molecular Modeling, 22(9), 203.

12. Gomes, I., Ayoub, M. A., Fujita, W., Jaeger, W. C., Pfleger, K. D., \& Devi, L. A. (2016). G protein-coupled receptor heteromers. Annual Review of Pharmacology and Toxicology, 56, 403-425.

13. Lan, T. H., Liu, Q., Li, C., Wu, G., Steyaert, J., \& Lambert, N. A. (2015). BRET evidence that beta2 adrenergic receptors do not oligomerize in cells. Scientific Reports, 5, 10166.

14. Ploier, B., Caro, L. N., Morizumi, T., Pandey, K., Pearring, J. N., Goren, M. A., Finnemann, S. C., Graumann, J., Arshavsky, V. Y., Dittman, J. S., Ernst, O. P., \& Menon, A. K. (2016). Dimerization deficiency of enigmatic retinitis pigmentosa-linked rhodopsin mutants. Nature Communications, 7, 12832.

15. Frederick, A. L., Yano, H., Trifilieff, P., Vishwasrao, H. D., Biezonski, D., Meszaros, J., Urizar, E., Sibley, D. R., Kellendonk, C., Sonntag, K. C., Graham, D. L., Colbran, R. J., Stanwood, G. D., \& Javitch, J. A. (2015). Evidence against dopamine D1/D2 receptor heteromers. Molecular Psychiatry, 20(11), 1373-1385.

16. Whorton, M. R., Jastrzebska, B., Park, P. S., Fotiadis, D., Engel, A., Palczewski, K., \& Sunahara, R. K. (2008). Efficient coupling of transducin to monomeric rhodopsin in a phospholipid bilayer. Journal of Biological Chemistry, 283(7), 4387-4394.

17. Kunishima, N., Shimada, Y., Tsuji, Y., Sato, T., Yamamoto, M., Kumasaka, T., Nakanishi, S., Jingami, H., \& Morikawa, K. (2000). Structural basis of glutamate recognition by a dimeric metabotropic glutamate receptor. Nature, 407(6807), 971-977.

18. Tateyama, M., Abe, H., Nakata, H., Saito, O., \& Kubo, Y. (2004). Ligand-induced rearrangement of the dimeric metabotropic glutamate receptor 1alpha. Nature Structural \& Molecular Biology, 11(7), 637-642.

19. Brock, C., Oueslati, N., Soler, S., Boudier, L., Rondard, P., \& Pin, J. P. (2007). Activation of a dimeric metabotropic glutamate receptor by intersubunit rearrangement. Journal of Biological Chemistry, 282(45), 33000-33008.

20. Xue, L., Rovira, X., Scholler, P., Zhao, H., Liu, J., Pin, J. P., \& Rondard, P. (2015). Major ligand-induced rearrangement of the heptahelical domain interface in a GPCR dimer. Nature Chemical Biology, 11(2), 134-140.

21. Techlovska, S., Chambers, J. N., Dvorakova, M., Petralia, R. S., Wang, Y. X., Hajkova, A., Nova, A., Frankova, D., Prezeau, L., \& Blahos, J. (2014). Metabotropic glutamate receptor 1 splice variants mGluR1a and mGluR1b combine in mGluR $1 \mathrm{a} / \mathrm{b}$ dimers in vivo. Neuropharmacology, 86, 329-336.

22. Milligan, G. (2009). G protein-coupled receptor hetero-dimerization: Contribution to pharmacology and function. British Journal of Pharmacology, 158(1), 5-14.

23. Maurel, D., Comps-Agrar, L., Brock, C., Rives, M. L., Bourrier, E., Ayoub, M. A., Bazin, H., Tinel, N., Durroux, T., Prezeau, L., Trinquet, E., \& Pin, J. P. (2008). Cell-surface protein-protein 
interaction analysis with time-resolved FRET and snap-tag technologies: Application to GPCR oligomerization. Nature Methods, 5(6), 561-567.

24. Geng, Y., Bush, M., Mosyak, L., Wang, F., \& Fan, Q. R. (2013). Structural mechanism of ligand activation in human GABA(B) receptor. Nature, 504(7479), 254-259.

25. James, J. R., Oliveira, M. I., Carmo, A. M., Iaboni, A., \& Davis, S. J. (2006). A rigorous experimental framework for detecting protein oligomerization using bioluminescence resonance energy transfer. Nature Methods, 3(12), 1001-1006.

26. Berthouze, M., Ayoub, M., Russo, O., Rivail, L., Sicsic, S., Fischmeister, R., Berque-Bestel, I., Jockers, R., \& Lezoualc'h, F. (2005). Constitutive dimerization of human serotonin 5-HT4 receptors in living cells. FEBS Letters, 579(14), 2973-2980.

27. Goin, J. C., \& Nathanson, N. M. (2006). Quantitative analysis of muscarinic acetylcholine receptor homo- and heterodimerization in live cells: Regulation of receptor down-regulation by heterodimerization. Journal of Biological Chemistry, 281(9), 5416-5425.

28. Guo, W., Urizar, E., Kralikova, M., Mobarec, J. C., Shi, L., Filizola, M., \& Javitch, J. A. (2008). Dopamine D2 receptors form higher order oligomers at physiological expression levels. EMBO Journal, 27(17), 2293-2304.

29. Xu, T. R., Ward, R. J., Pediani, J. D., \& Milligan, G. (2011). The orexin $\mathrm{OX}(1)$ receptor exists predominantly as a homodimer in the basal state: Potential regulation of receptor organization by both agonist and antagonist ligands. Biochemical Journal, 439(1), 171-183.

30. Herrick-Davis, K., Grinde, E., Cowan, A., \& Mazurkiewicz, J. E. (2013). Fluorescence correlation spectroscopy analysis of serotonin, adrenergic, muscarinic, and dopamine receptor dimerization: the oligomer number puzzle. Molecular Pharmacology, 84 (4), 630-642.

31. Parmar, V. K., Grinde, E., Mazurkiewicz, J. E., \& Herrick-Davis, K. (2017). Beta2-adrenergic receptor homodimers: Role of transmembrane domain 1 and helix 8 in dimerization and cell surface expression. Biochimica et Biophysica Acta, 1859(9 PtA), $1445-1455$

32. Jastrzebska, B., Comar, W. D., Kaliszewski, M. J., Skinner, K. C., Torcasio, M. H., Esway, A. S., Jin, H., Palczewski, K., \& Smith, A. W. (2017). A G protein-coupled receptor dimerization interface in human cone opsins. Biochemistry, 56(1), 61-72.

33. Harding, P. J., Attrill, H., Boehringer, J., Ross, S., Wadhams, G. H., Smith, E., Armitage, J. P., \& Watts, A. (2009). Constitutive dimerization of the G-protein coupled receptor, neurotensin receptor 1, reconstituted into phospholipid bilayers. Biophysical Journal, 96(3), 964-973.

34. Hern, J. A., Baig, A. H., Mashanov, G. I., Birdsall, B., Corrie, J. E., Lazareno, S., Molloy, J. E., \& Birdsall, N. J. (2010). Formation and dissociation of M1 muscarinic receptor dimers seen by total internal reflection fluorescence imaging of single molecules. Proceedings of the National Academy of Sciences of the United States of America, 107(6), 2693-2698.

35. Kasai, R. S., Suzuki, K. G., Prossnitz, E. R., Koyama-Honda, I., Nakada, C., Fujiwara, T. K., \& Kusumi, A. (2011). Full characterization of GPCR monomer-dimer dynamic equilibrium by single molecule imaging. Journal of Cell Biology, 192(3), 463-480.

36. Calebiro, D., Rieken, F., Wagner, J., Sungkaworn, T., Zabel, U., Borzi, A., Cocucci, E., Zurn, A., \& Lohse, M. J. (2013). Singlemolecule analysis of fluorescently labeled G-protein-coupled receptors reveals complexes with distinct dynamics and organization. Proceedings of the National Academy of Sciences of the United States of America, 110(2), 743-748.

37. Teichmann, A., Gibert, A., Lampe, A., Grzesik, P., Rutz, C., Furkert, J., Schmoranzer, J., Krause, G., Wiesner, B., \& Schulein,
R. (2014). The specific monomer/dimer equilibrium of the corticotropin-releasing factor receptor type 1 is established in the endoplasmic reticulum. Journal of Biological Chemistry, 289(35), 24250-24262.

38. Comar, W. D., Schubert, S. M., Jastrzebska, B., Palczewski, K., \& Smith, A. W. (2014). Time-resolved fluorescence spectroscopy measures clustering and mobility of a $\mathrm{G}$ protein-coupled receptor opsin in live cell membranes. Journal of the American Chemical Society, 136(23), 8342-8349.

39. Tabor, A., Weisenburger, S., Banerjee, A., Purkayastha, N., Kaindl, J. M., Hubner, H., Wei, L., Gromer, T. W., Kornhuber, J., Tschammer, N., Birdsall, N. J., Mashanov, G. I., Sandoghdar, V., \& Gmeiner, P. (2016). Visualization and ligand-induced modulation of dopamine receptor dimerization at the single molecule level. Scientific Reports, 6, 33233.

40. Wang, M., Pei, L., Fletcher, P. J., Kapur, S., Seeman, P., \& Liu, F. (2010). Schizophrenia, amphetamine-induced sensitized state and acute amphetamine exposure all show a common alteration: increased dopamine D2 receptor dimerization. Molecular brain, 3, 25.

41. Beaulieu, J. M., \& Gainetdinov, R. R. (2011). The physiology, signaling, and pharmacology of dopamine receptors. Pharmacological Reviews, 63(1), 182-217.

42. Guo, W., Shi, L., \& Javitch, J. A. (2003). The fourth transmembrane segment forms the interface of the dopamine D2 receptor homodimer. Journal of Biological Chemistry, 278(7), 4385-4388.

43. Ng, G. Y., O’Dowd, B. F., Lee, S. P., Chung, H. T., Brann, M. R., Seeman, P., \& George, S. R. (1996). Dopamine D2 receptor dimers and receptor-blocking peptides. Biochemical and Biophysical Research Communications, 227(1), 200-204.

44. Han, Y., Moreira, I. S., Urizar, E., Weinstein, H., \& Javitch, J. A (2009). Allosteric communication between protomers of dopamine class A GPCR dimers modulates activation. Nature Chemical Biology, 5(9), 688-695.

45. Zawarynski, P., Tallerico, T., Seeman, P., Lee, S. P., O’Dowd, B. F., \& George, S. R. (1998). Dopamine D2 receptor dimers in human and rat brain. FEBS Letters, 441(3), 383-386.

46. Mercier, J. F., Salahpour, A., Angers, S., Breit, A., \& Bouvier, M. (2002). Quantitative assessment of beta 1- and beta 2-adrenergic receptor homo- and heterodimerization by bioluminescence resonance energy transfer. Journal of Biological Chemistry, 277(47), 44925-44931.

47. Herrick-Davis, K., Grinde, E., \& Weaver, B. A. (2007). Serotonin 5 -HT(2C) receptor homodimerization is not regulated by agonist or inverse agonist treatment. European Journal of Pharmacology, $568(1-3), 45-53$.

48. Guo, W., Shi, L., Filizola, M., Weinstein, H., \& Javitch, J. A. (2005). Crosstalk in G protein-coupled receptors: Changes at the transmembrane homodimer interface determine activation. Proceedings of the National Academy of Sciences of the United States of America, 102(48), 17495-17500.

49. Percherancier, Y., Berchiche, Y. A., Slight, I., Volkmer-Engert, R., Tamamura, H., Fujii, N., Bouvier, M., \& Heveker, N. (2005). Bioluminescence resonance energy transfer reveals ligandinduced conformational changes in CXCR4 homo- and heterodimers. Journal of Biological Chemistry, 280(11), 9895-9903.

50. Hayes, G., Biden, T. J., Selbie, L. A., \& Shine, J. (1992). Structural subtypes of the dopamine $\mathrm{D} 2$ receptor are functionally distinct: expression of the cloned D2A and D2B subtypes in a heterologous cell line. Molecular Endocrinology, 6(6), 920-926.

51. Rock, C. O., \& Cronan, Jr., J. E. (1979). Re-evaluation of the solution structure of acyl carrier protein. Journal of Biological Chemistry, 254(19), 9778-9785.

52. George, N., Pick, H., Vogel, H., Johnsson, N., \& Johnsson, K. (2004). Specific labeling of cell surface proteins with chemically 
diverse compounds. Journal of the American Chemical Society, 126(29), 8896-8897.

53. Iino, R., Koyama, I., \& Kusumi, A. (2001). Single molecule imaging of green fluorescent proteins in living cells: E-cadherin forms oligomers on the free cell surface. Biophysical Journal, 80 (6), 2667-2677.

54. Koyama-Honda, I., Ritchie, K., Fujiwara, T., Iino, R., Murakoshi, H., Kasai, R. S., \& Kusumi, A. (2005). Fluorescence imaging for monitoring the colocalization of two single molecules in living cells. Biophysical Journal, 88(3), 2126-2136.

55. Fujiwara, T., Ritchie, K., Murakoshi, H., Jacobson, K., \& Kusumi, A. (2002). Phospholipids undergo hop diffusion in compartmentalized cell membrane. Journal of Cell Biology, 157(6), 1071-1081.

56. Dunne, P. D., Fernandes, R. A., McColl, J., Yoon, J. W., James, J. R., Davis, S. J., \& Klenerman, D. (2009). DySCo: quantitating associations of membrane proteins using two-color single-molecule tracking. Biophysical Journal, 97(4), L5-L7.
57. Suzuki, K. G., Kasai, R. S., Hirosawa, K. M., Nemoto, Y. L., Ishibashi, M., Miwa, Y., Fujiwara, T. K., \& Kusumi, A. (2012). Transient GPI-anchored protein homodimers are units for raft organization and function. Nature Chemical Biology, 8(9), 774-783.

58. Gardner, B., \& Strange, P. G. (1998). Agonist action at D2(long) dopamine receptors: Ligand binding and functional assays. British Journal of Pharmacology, 124(5), 978-984.

59. Hall, D. A., \& Strange, P. G. (1997). Evidence that antipsychotic drugs are inverse agonists at D2 dopamine receptors. British Journal of Pharmacology, 121(4), 731-736.

60. Rodriguez-Frade, J. M., Vila-Coro, A. J., de Ana, A. M., Albar, J. P., Martinez, A. C., \& Mellado, M. (1999). The chemokine monocyte chemoattractant protein-1 induces functional responses through dimerization of its receptor CCR2. Proceedings of the National Academy of Sciences of the United States of America, 96 (7), 3628-3633. 